\title{
SOSIALISASI MITIGASI BENCANA LONGSOR DI DAERAH HAMBALANG, KECAMATAN CITEREUP, KABUPATEN BOGOR
}

\author{
Lili Fauzielly, Lia Jurnallah, Luthfan Harisan Jihadi, Muhammad Aditio, \\ Taufiq Hadi Ramadhan, dan Iqbal Jabbari Mufti \\ ${ }^{1}$ Fakultas Teknik Geologi, Universitas Padjadjaran \\ E-mail: lili.fauzielly@unpad.ac.id
}

\begin{abstract}
ABSTRAK. Bencana longsor merupakan salah satu peristiwa alam yang paling umum terjadi di Indonesia, terutama dalam waktu musim hujan. Sebagai salah satu langkah untuk mengurangi kerugian dari peristiwa bencana longsor adalah dengan melakukan kegiatan sosialisasi mengenai mitigasi bencana longsor, dengan tujuan untuk meningkatkan kesadaran dan kesiapsiagaan mayarakat terhadap bencana longsor. Objek dari kegiatan sosialisasi ini ditujukan untuk anak-anak usia dini di Sekolah Dasar Negeri 2 Hambalang, yang pelaksanaannya didampingi oleh guru sekolah. Indikator keberhasilan Dalam proses pembelajaran, diadakan dua kali uji pengetahuan, bencana sebelum dan setelah proses pemberian materi ajar dilakukan. Nilai uji tersebut yang didapat kemudian dibandingkan dan digunakan sebagai parameter dari keberhasilan pembelajaran. Didapatkan peningkatan nilai rata-rata sebesar 23.12\% dan peningkatan murid yang lolos ujian sebesar $22.53 \%$. Berdasarkan perbandingan hasil uji, dapat disimpulkan bahwa ada peningkatan pengetahuan murid yang diuji setelah kegiatan pembelajaran selesai dilakukan. Diharapkan dengan berhasilnya kegiatan sosialisasi tersebut dapat berkontribusi dalam mengurangi resiko bencana longsor di daerah Hambalang.
\end{abstract}

Kata kunci: longsor, mitigasi bencana, sosialisasi

\section{THE SOCIALIZATION OF LANDSLIDE DISASTER MITIGATION IN THE HAMBALANG AREA, CITEUREUP DISTRICT, BOGOR REGENCY}

\begin{abstract}
Lanslide disaster is one of disasters that commonly occur in Indonesia, especially in the rain season. As a method of disaster mitigation in order to minimalize the risk of landslide disaster, this social work conducted by mean of raising disaster awareness and preparedness on society. The object in this social work are young children who studied at Primary Public School 2 Hambalang, supervised by teachers. In the process of teaching, two disaster knowledge tests were conducted, before and after learning material was given. The results of both tests are compared then used as parameter of teaching accomplishment. There are increases in average value by $23.12 \%$ and total number of students who passed the test by $22.53 \%$. According to the results comparison, we can conclude that there is an improvement of knowledge of tested students after teaching proccess was done. We hope with that the achievement of this social work may contribute to minimalize the risk of landslide disaster in Hambalang.
\end{abstract}

Keywords: landslide; disaster mitigation; socialization

\section{PENDAHULUAN}

Bencana longsor terjadi hampir setiap tahun di Indonesia dan paling banyak ketika musim hujan. Berdasarkan data yang dipublikasikan oleh Badan Nasional Penanggulangan Bencana (BNPB), 2017, kejadian longsor di daerah Bogor terjadi sebanyak 147 kali dalam lingkup tahun 2009-2017 dengan rata-rata 16 kali kejadian dan 431 korban bencana setiap tahunnya (Tabel 1.1). Secara statistik, Kabupaten Bogor merupakan daerah yang rawan bencana longsor. Di dalam Peta Zona Kerentanan Tanah Lembar Bogor (Pusat Vulkanologi dan Mitigasi Bencana Geologi, PVMBG, 2012), dinyatakan daerah Hambalang termasuk ke dalam kategori bencana longsor tingkat menengah sampai tinggi. Atas dasar peta tersebut, perlu dilakukan sosialisasi mengenai mitigasi bencana longsor di daerah tersebut dengan tujuan untuk meminimalisir resiko bencana (Gambar 1.1). Sekolah Dasar Negeri (SDN) 2 Hambalang memiliki jumlah murid terbanyak dan lokasinya berada di dekat puncak bukit Hambalang. Lokasi ini termasuk dalam kategori rentan akan pergerakan tanah, Sehingga kegiatan sosialisasi dilakukan di sekolah tersebut.

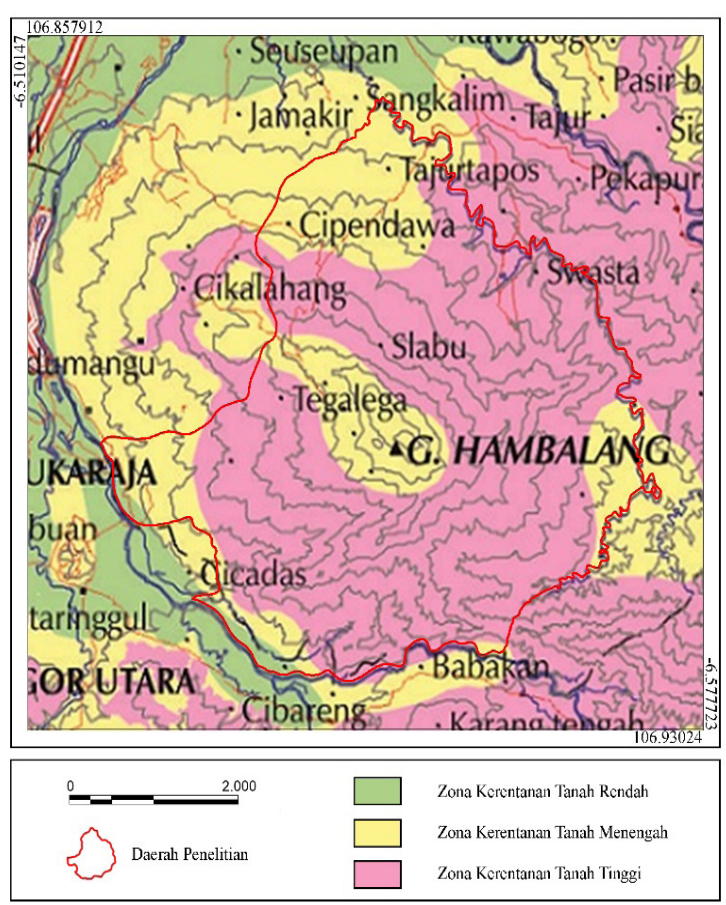

Gambar 1. Peta Zona Kerentanan Tanah dari PVMBG (tanpa tahun), yang dimodifikasi (2012) 
Tabel 1.1 Kejadian Lonsor dan Dampak Bencana 2009-2017, BNPB (2017)

\begin{tabular}{|c|c|c|c|c|c|c|c|c|c|c|c|}
\hline \multirow{2}{*}{ Tahun } & \multirow{2}{*}{ Jumlah } & \multicolumn{3}{|c|}{ Korban Jiwa } & \multicolumn{4}{|c|}{ Rumah } & \multicolumn{3}{|c|}{ Fasilitas } \\
\hline & & Tewas & $\begin{array}{l}\text { Luka- } \\
\text { luka }\end{array}$ & $\begin{array}{l}\text { Meng- } \\
\text { ungsi }\end{array}$ & $\begin{array}{c}\text { Rusak } \\
\text { Berat }\end{array}$ & $\begin{array}{c}\text { Rusak } \\
\text { Sedang }\end{array}$ & $\begin{array}{l}\text { Rusak } \\
\text { Ringan }\end{array}$ & $\begin{array}{c}\text { Ter- } \\
\text { timbun }\end{array}$ & $\begin{array}{l}\text { Kese- } \\
\text { hatan }\end{array}$ & $\begin{array}{c}\text { Periba- } \\
\text { datan }\end{array}$ & $\begin{array}{c}\text { Pendi- } \\
\text { dikan }\end{array}$ \\
\hline 2009 & 2 & 0 & 2 & 0 & 13 & 0 & 1 & 0 & 0 & 0 & 0 \\
\hline 2010 & 7 & 7 & 10 & 592 & 62 & 33 & 47 & 0 & 0 & 0 & 2 \\
\hline 2011 & 4 & 14 & 4 & 223 & 16 & 0 & 29 & 0 & 0 & 0 & 0 \\
\hline 2012 & 34 & 13 & 13 & 589 & 33 & 59 & 98 & 0 & 0 & 1 & 1 \\
\hline 2013 & 7 & 9 & 5 & 198 & 20 & 7 & 1 & 0 & 0 & 2 & 0 \\
\hline 2014 & 29 & 24 & 29 & 947 & 197 & 5 & 93 & 1893 & 0 & 3 & 2 \\
\hline 2015 & 16 & 14 & 5 & 388 & 49 & 52 & 49 & 0 & 1 & 4 & 0 \\
\hline 2016 & 16 & 1 & 1 & 283 & 18 & 12 & 9 & 0 & 0 & 0 & 2 \\
\hline 2017 & 32 & 1 & 7 & 502 & 22 & 25 & 48 & 0 & 0 & 2 & 2 \\
\hline
\end{tabular}

METODE

\section{Analisis Kerentanan Longsor}

Pembuktian kerentanan longsor dilakukan dengan cara melakukan analisis morfometri yang dikorelasikan dengan data sekunder. Analisis geomorfologi yang umum dilakukan terkait tiga aspek, yaitu: morfograf, morfometri, dan morfogenesis. Kemiringan lereng, kondisi cekungan aliran sungai, serta kondisi sungai, dijadikan dasar interpretasi dalam menentukan zonasi wilayah rawan bencana longsor. Dengan beberapa indikator, yaitu:

1. Dengan asumsi sifat fisik batuannya sama, maka lereng bukit yang curam akan lebih rawan longsor dibandingkan dengan lereng lebih landai (Jihadi, et al. 2015).

2. Kerapatan sungai diasumsikan sebagai indeks kerentanan longsor, yaitu semakin tinggi tingkat kerapatan sungainya maka semakin tinggi potensi longsor yang dipicu oleh hujan (Hasegawa, et al. 2013). Peluang terjadi longsor semakin tinggi ketika lereng berada dalam kondisi basah (Jihadi, et al. 2015).

\section{Proses Pembelajaran}

Penyampaian materi dilakukan menggunakan media audio dan visual, dengan media ajar berupa infografik, video, dan pembacaan materi. Dalam proses pembelajaran, murid dipacu untuk aktif bertanya dan menjawab pertanyaan lisan. Untuk mencapai metoda pembelajaran tersebut, salah satunya adalah dengan memberikan hadiah kepada siswa yang menjawab pertanyaan dengan benar. Metoda pembelajaran lainnya adalah dengan pendekatan belajar sambil bermain, sehingga selama proses pembelajaran berlangsung, materi ajar dapat diserap dengan lebih baik.

Evaluasi dilakukan dilakukan dengan cara membandingkan pengetahuan dan pemahaman siswa, sebelum dan sesudah dilakukannya sosialisasi bencana longsor. Tingkat pengetahuan murid diidentifikasi berdasarkan kemampuan murid dalam menjawab sepuluh pertanyaan Siswa yang dinyatakan lulus ujian apabila mencapai nilai diatas lima, dan nilai enam menjadi threshold kelulusan.

\section{HASIL DAN PEMBAHASAN}

Batuan penyusun daerah Hambalang terdiri atas batuan vulkanik berumur kuarter yang menunpang tidak selaras di atas satuan batulempung Anggota Formasi Jatiluhur (Badan Geologi, 2015). Hasil perhitungan kemiringan lereng yang ditentukan berdasarkan klasifikasi Van Zuidam (1985) (Gambar 3), menunjukkan daerah Hambalang secara umum memiliki kemiringan lereng agak curam $\left(8^{\circ}-16^{\circ}\right)$ hingga curam $\left(16^{\circ}-35^{\circ}\right)$. Kerapatan sungai di daerah ini cukup tinggi dan seragam, dengan rentang nilai 16-24 dan dengan nilai rata-rata sebesar 20 . (Gambar 4). Berdasarkan hasil perhitungan di atas,-daerah Hambalang memiliki karakteristik hampir homogenik yang rentan akan pergerakan tanah Kesimpulan ini selaras dengan Peta Zona Kerentanan Gerakan Tanah dari PVMBG (2012)

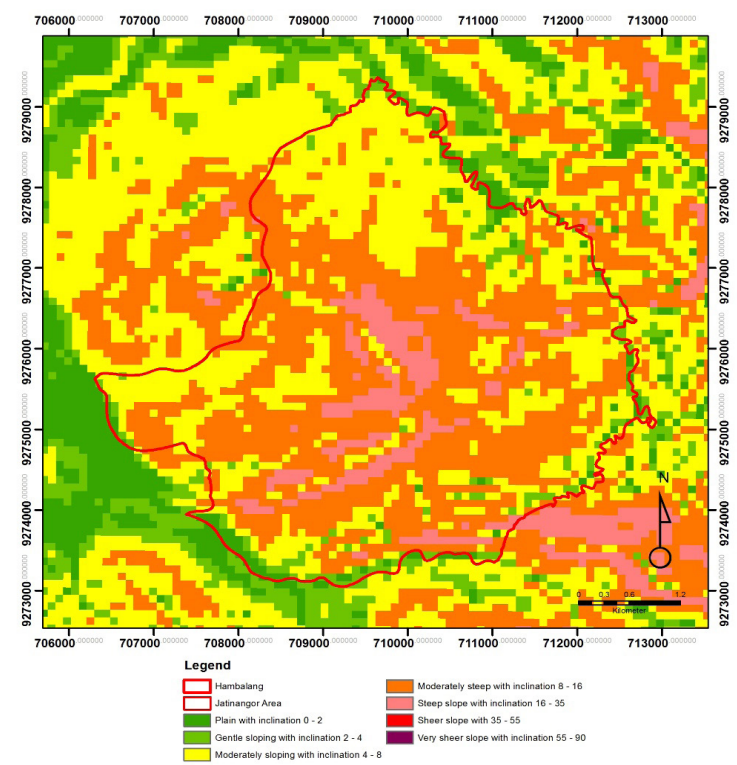

Gambar 3. Peta Kemiringan Lereng berdasarkan Klasifikasi Lereng Van Zuidam (1985) 


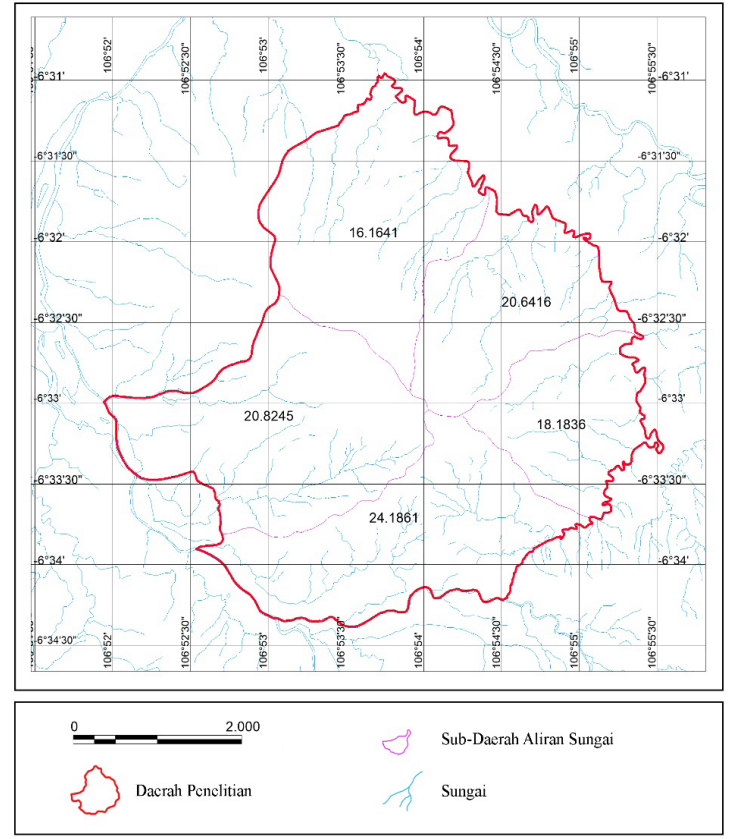

Gambar 4. Peta Sub-Daerah Aliran Sungai beserta Nilai Kerapatan Sungai

\section{Hasil Evaluasi}

Sebelum pemberian materi, umumnya murid hanya mampu menjawab 4 hingga 5 dari 10 pertanyaan, Dari seluruh peserta sosialisasi yang jumlahnya 71 siswa, yang berhasil lulus ujian sebanyak 30 orang. Setelah dilakukan pembelajaran, umumnya murid dapat menjawab dengan benar sebanyak 6 hingga 8 dari 10 pertanyaan. Dari hasil test tersebut, jumlah siswa yang lulus ujian sebanyak 46 orang atau meningkat sebesar $23.12 \%$.

Tabel 1. Frekuensi Nilai Ujian Murid SDN2 Hambalang

\begin{tabular}{cccc}
\hline \multicolumn{1}{c}{ Sebelum } & \multicolumn{2}{c}{ Sesudah } \\
\hline Nilai $<6$ & 19 & Nilai $<6$ & 25 \\
Nilai 6 & 7 & Nilai 6 & 19 \\
Nilai 7 & 1 & Nilai 7 & 7 \\
Nilai 8 & 2 & Nilai 8 & 9 \\
Nilai 9 & 1 & Nilai 9 & 8 \\
Nilai 10 & 71 & Nilai 10 & 3 \\
Jumlah Lulus & 30 & Jumlah & 46 \\
\hline
\end{tabular}

\section{SIMPULAN}

Hambalang merupakan daerah yang rentan akan bencana longsor, sehingga kegiatan sosialisasi yang dilakukan telah tepat sasaran. Berdasarkan hasil dari pengujian terhadap nilai murid, dapat dinyatakan bahwa tingkat pemahaman materi penyuluhan bahaya longsor pada murid telah meningkat. Dengan demikian dapat disimpulkan bahwa kegiatan pembelajaran memberikan pengaruh terhadap kenaikan pemahaman murid terhadap bencana longsor. Peserta pelatihan sosialisasi juga menyampaikan beberapa pesan, saran, dan kesan saat di lokasi, sehingga data tersebut bisa menjadi bahan evaluasi pelaksanaan kegiatan pelatihan.

\section{UCAPAN TERIMAKASIH}

Kami ucapkan terimakasih kepada pihak Direktorat Riset PKM dan Inovasi Unpad atas kesempatan dan kepercayaan yang telah diberikan, serta kami ucapkan terimakasih kepada pihak SDN 2 Hambalang atas kerjasamanya sehingga kegiatan sosialisasi ini dapat terlaksana dengan baik.

\section{DAFTAR PUSTAKA}

Badan Geologi. 2015. Laporan Singkat Pemeriksaan Gerakan Tanah Di Desa Hambalang, Kec. Citeureup, Kab. Bogor, Provinsi Jawa Barat. (http://www.vsi.esdm.go.id/index.php/ gerakan-tanah/kejadian-gerakan-tanah/945laporan-singkat-pemeriksaan-gerakan-tanahdi-desa-hambalang-kec-citeureup-kab-bogorprovinsi-jawa-barat, diakses 14 November 2017)

Badan Penanggulangan Bencana Nasional. 2017. Bencana Menurut Jenisnya Kab/Kota (Bogor). (http://bnpb.cloud/bnpb/tabel1, diakses 14 November 2017).

Hasegawa, S. Nonomura, A. Nakai, S. dan Dahal, R. K. 2013. Drainage Density as Rainfall Induced Landslides Susceptibility in Small Catchment Area. International Journal of Lanslide and Environment Vol. 1 No. 1: hlm. 27-28

Jihadi, L. H. Azy F. N. Anural, M. B. dan Zakaria, Z. 2015. Engineering Geological Mapping as a Part of Lanslide Mitigation at Surface Mining Site in Desa Licin, Sumedang, West Java, Indonesia. Engineering Geology for Society and Territory-Volume 2. Cham, Switzerland: Springer International Publishing Switzerland

Jihadi, L. H. Zakaria, Z. Helmi, F. Azy, F. N. Darana, A.R. dan Surmayono, S. 2015. Probability of Failure based on Morphometric Characteristic of Slope in Padang Pariaman, West Sumatra, Indonesia. 10 $0^{\text {th }}$ Asian Regional Conference of International Association for Engineering Geology and the Environment (IAEG) 2015: Landslides, Debris flows, and Rock Mass Collapse. Index 291083503

Noor, D. 2010. Geomorfologi. Bogor: Universitas Pakuan

Pusat Vulkanologi dan Mitigasi Bencana Geologi, (2012). Peta Zona Kerentanan Gerakan Tanah Kota dan Kabupaten Bogor, Provinsi Jawa Barat. Bandung: Badan Geologi 